\title{
EL DIARIO DE CLARA
}

\author{
Helga Martínez Pallarés
}

«A quien lea esta carta:

Si estas líneas llegan a sus manos, sin duda querrá decir que por fin se ha hecho justicia. No tiene que preocuparse de mí, no me ha ocurrido nada malo. Significa sólo que aunque he decidido al fin contar mi historia, al final no he tenido valor para dar la cara por el delito cometido, y estaré en alguna parte, muy lejos, en la otra orilla del olvido. Donde nadie pueda venir a pedirme cuentas. Ni a hablarme de Clara. Ni siquiera la propia Clara (me querría morir sólo de verla).

Cuando todo esto empezó, Clara Morales era mi amiga, ¿sabe? Nos conocimos cuando éramos unos chiquillos, una tarde de septiembre, al salir del colegio. Teníamos... no sé, unos trece, catorce años, quizá. Hace tanto tiempo que ya no soy capaz de perfilar los recuerdos y dar con la fecha exacta. Clara por aquel entonces acababa de comenzar el bachillerato. Yo, en cambio, empezaba el segundo curso, por eso no la había conocido hasta entonces. De no haber sido así habríamos sido amigos mucho antes, eso seguro. Era imposible coincidir con su sonrisa y no congeniar con ella. A mí me parecía la visión de una cascada en pleno desierto, con sus ojos enormes abiertos al paisaje abigarrado de Madrid, y su risa de cristal roto contradiciendo por sorpresa la juventud de su rostro.

Nos caímos bien al instante. Bueno, para ser justos, yo le caí bien a ella. Ella para mí siempre fue algo más. Una muñeca extraña. Hipnótica. Y un misterio. Alternaba la risa más alegre que yo había oído nunca con silencios de pozo insondable que la perturbaban en sus "días raros".

Entre unas y otras, pasamos los años en un permanente intercambio de papeles. Aunque, en realidad, no alternábamos nada en realidad: yo era siempre la enredadera desnortada que crecía en torno a ella. Ella, en cambio, no crecía alrededor de nadie, era agreste y vivaz, sin rumbo claro. Vivía. Sin más.

Luego, demasiado pronto, llegó mi último año. Yo no era un buen estudiante, estaba más lleno de preguntas que de conocimientos. O peor: me sentía absolutamente incapaz de decidir qué quería hacer después. Tantas vueltas le di,

Tercer Premio del

I Concurso de Relatos Breves AEN. 
que tomé una decisión impensable para un estudiante. Sentado en el examen final (en blanco), asumí dos verdades irrefutables en mi vida: que lo acabaría tirando todo por la borda con tal de seguir con ella, y que ella... nunca me lo perdonaría.

En su momento escapé a las preguntas de Clara, que no podía explicarse que fuera a repetir el último curso. Mentí, le eché la culpa a los nervios de última hora, a un sinfín de patrañas por el estilo. Clara quiso creerme, o no quiso insistir, apiadada por mi discurso compungido, de derrotado por sorpresa en una contienda que se daba por ganada de antemano. No dijo nada más, le echó humor al asunto y optó por intentar mostrar el lado bueno de la historia. Al fin y al cabo, un año más juntos no era ningún drama, ¿no? Dios mío, ¡si supiera que la historia tenía dos tramas diferentes...! Se hubiera sentido tan estafada que la hubiera perdido ya por aquel entonces.

Le echó al buen tiempo buena cara, pasamos el último curso juntos, como yo quería, y cuando por fin decidió qué carrera iba a estudiar aproveché su entusiasmo para optar por la misma yo también.

Fue así como empezamos a estudiar Filología hispánica. Clara desde siempre quiso ser escritora. Se preparaba a conciencia, estudiaba literatura, soñaba con presentarse a cuantos certámenes encontraba a su paso. Y me insistía a mí, fervientemente, casi con vehemencia, para que me presentara a los mismos concursos a la vez. Por su actitud casi hubiera jurado que ella no tenía ninguna intención de ganar, que lo estaba posponiendo, esperando a que yo le adelantara primero para poder brillar ella después... Tanto era así que casi todo lo que ella escribía terminaba por descartarlo, eliminarlo o, simplemente, abandonarlo en mi casa, como si no tuviera importancia. A pesar de ser magnífica, perturbadora en sus palabras, no quería llegar a mostrarlas, como si no fuera el momento... Yo guardaba todo lo que caía en mis manos, por miedo a que en uno de sus arrebatos lo destruyera sin más. La mesa de mi cuarto, los armarios, rebosaban de textos de ella, desperdigados, abandonados a su suerte.

Mis creaciones, en cambio, sólo eran una tremenda farsa. En cada ocasión pergeñaba, siempre en el último momento, algunas líneas al azar. Cualquier cosa, garabatos... Llegué incluso a copiar algún texto ya publicado de otros autores, modificando simplemente algunas palabras (y rezando cada vez para que no me pillaran, por no decepcionarla a ella). Por suerte, o por desgracia, nunca tuve ninguna posibilidad. Pero lo peor era ella, lo que me mataba, era verla permaneciendo en la sombra por no hacerme sombra a mí.

De pronto, un mal día Clara se desencantó. Contra todo pronóstico, decidió ser profesora de instituto. La intenté convencer por todos los medios. Me pareció un sucedáneo, una vía de escape para alguien de su talento. Pero ella no quiso escucharme. Simplemente buscó trabajo y en sólo unas semanas encontró una ocupación menor, y se olvidó de escribir. "Ya no me divertía - me dijo Clara - , 
MÁRGENES DE LA PSIQUIATRÍA Y HUMANIDADES

no tenía suerte o simplemente no valía para escribir”. Sin más. Dio un carpetazo a sus sueños. Lo dejó.

Para mí seguir escribiendo ya no tenía sentido. Además, todo había sido un truco de prestidigitador barato, una excusa barata para pasar más tiempo junto a ella. El problema vino entonces, cuando yo quise hacer lo mismo. Clara nunca lo admitió. Se culpó a sí misma, decía que por su desencanto me estaba obligando a abandonar a mí. Lloró y lloró durante días, se convirtió en un fantasma, llegó a preocuparme que se perdiera en las sombras para siempre, que se volviera loca sin más.

Empecé a temer que, decepcionada de todo, decidiera dejarme. Y me volví loco, no supe soportar la imagen de una vida sin ella. Empecé a escribir. A escribir de verdad, compulsivamente, sin comer y sin dormir apenas, a deshoras. Las noches se me iban entre borradores, inicios... y tachones. No valgo para esto, joder, simplemente hay que tener una pasta que yo no tengo. Ni siquiera sé cómo fui capaz de engañar a Clara tantos años. Lo que valía en nuestra historia era la imagen que ella reflejaba en sus ojos, el engaño que fabricó para hacerme sentir alguien importante, algo especial.

Hace seis o siete meses, apareció en mi casa. Reunión de pastores: ella, sus ojos, su sonrisa, la voz. Y yo de oveja muerta. Muerta de pena, muerta de rabia, muerto de amor frustrado. De sinrazón.

- ¿Qué te pasa?

- Nada. Estoy cansado, nada más.

- Algo te pasa. Lo veo en tus ojos. Que estás como si no estuvieras. Que estás en otra parte.

-No, Clara, no te preocupes. Es sólo que... no puedo, no quiero seguir escribiendo. Creo que nunca debí hacerlo. Me arrastraste, llegué a creer que podría. Pero esta no es mi vida, Clara. Es la tuya.

No contestó. Salió dando un portazo. Adiós, Clara. Adiós.

Esa noche la pasé conmigo mismo y con mi fantasma, asumiendo que no tenía ningún sentido seguir con la película de serie B que me había organizado para vivirla. Con una copa rota en las manos, sin valor para clavármela en las entrañas y justificarme a mí mismo.

Y fue al cabo de la madrugada cuando decidí matarme a mí mismo de la manera más cruel que se me ocurrió. Revolví los antiguos cajones, las estanterías, repletas, en busca del fondo, de lo más antiguo. Escogí una de las novelas del principio de Clara, un texto viejo, de cuando empezábamos a ser. A existir. Le cambié el nombre, lo metí en un sobre y lo envié al primer concurso que encontré (uno grande, tanto que nunca me hubiera atrevido en otras circunstancias). Y mire usted, me llamaron la semana pasada para decirme que soy famoso. Y rico. Y que vaya a la tele a presentar mi mentira en el telediario. La novela que le robé 
a Clara. Y no me preocupa salir en público a decir que la obra no es mía, lo que me preocupa es la conciencia clara de que ella me dejará precisamente por eso. Porque es la suya y no la mía. Porque su sueño no era publicar nada. Su sueño, y su labor, era únicamente jalearme a mí.

En Madrid, 3 de octubre de 2012».

- La verdad, doctor, no sé si este ejercicio me va a servir para algo. Ya sé, me lo han explicado, que toda esta historia parece que me la he inventado yo en mi cabeza. Que mi libro no puede ser de Clara porque ella nunca estudió conmigo, sólo es la camarera que me sirve el café por las mañanas desde hace años. Y que mi enfermedad me ha hecho inventarme una historia para ella también. Pero es que es tan real, doctor, tan real... Y si ahora me curan, con pastillas, o con hipnosis o con lo que sea, ¿me la van a robar? Porque yo no podría vivir sin Clara, doctor, no podría... 